\title{
Estética Natural e Ética Ambiental, QUE RELAÇÃo?
}

\author{
Maria José Varandas
}

(Centro de Filosofia da Universidade de Lisboa)

\section{I}

Quando John Muir (1838-1914) contemplou pela primeira vez a beleza pujante da Sierra Nevada pensou que a qualidade estética da natureza comportava uma dimensão objectiva de raiz divina, apenas maculada pela imisção humana.

O mesmo não se passou, anos mais tarde, com William Mulholland (1855-1935), chefe do Departamento de Água e Energia de Los Angeles que, na ânsia de canalizar água para a cidade, não reparou na beleza da Sierra, com as suas inúmeras e voláteis cascatas, as suas elegantes formas moldadas pelos glaciares, as suas magníficas e gigantes sequóias, a sua rica e multi-colorida fauna e flora. Não, não reparou no magnífico espectáculo cénico diante dos seus olhos, apenas viu os agricultores e os habitantes da região e, em função deles, lançou uma proposta ao superintendente do parque Yosemite para represar todo o vale, convertendo-o num imenso reservatório de utilidade pública.

A sua proposta não dava conta de um efeito incontroverso - a aniquilação de um espaço de uma beleza irradiante. E foi, justamente, esse valor estético que salvou o vale, embora o mesmo não tenha acontecido em outros trechos da região que, em anos subsequentes e apesar das movimentações públicas em prol da estética natural, foram transformados em gigantescas lagoas.

Nos conflitos gerados pela relação do homem com a natureza, os valores estéticos têm constituído, na prática, um poderoso e decisivo argumento na defesa e preservação das realidades naturais, contribuindo, juntamente com os de ordem moral, para complementar os argumentos de 
natureza tendencialmente instrumental (Sagoff, 1991) ${ }^{1}$. A este respeito o filósofo ambiental Baird Callicott afirma:

"No que toca à conservação e gestão de recursos, a estética natural tem sido historicamente, na verdade, muito mais relevante do que a ética ambiental. Grande parte das decisões conservacionistas foram motivadas mais pela estética do que pelos valores éticos, mais pela beleza do que pelo dever." (Callicott in Carlson\&Lintott (ed.), 2008:1)

Entre outros aspectos e numa primeira análise, tal facto justificar-se-á, porventura, pela imediatez perceptiva da experiência estética da natureza e pela respectiva qualidade de gerar o envolvimento e compromisso no sujeito, induzindo neste um sentimento de inclusão e continuidade com o meio natural (Berleant, 1992:4). Tratar-se-á, porventura, de uma experiência total, já que convoca todos os sentidos - a visão, seguramente, mas também o olfacto, a audição, o tacto, o sabor - e, ao mesmo tempo, totalitária, enquanto evocação de uma identificação simbiótica com o Todo, tal como expressivamente Rosario Assunto descreve:

"A paisagem com os seus aromas, mas também com as suas cores, as suas luzes. Com o seu céu, as suas águas, as suas rochas, a sua vegetação, as suas aves e insectos e animais de todo o tipo; que chega aos nossos pulmões, entra-nos literalmente no sangue, e expande-se pelos membros, fazendo-nos sentir unos com a natureza: e exalta o nosso ser natureza, a natureza que está em nós e reaviva-a; e dela faz objecto de deleite para a alma, suscitando em nós a alegria da nossa identificação com a natureza, de fazer da sua a nossa alegria." (in A. Veríssimo Serrão (coord.), 2011:367).

Neste ponto, não esqueçamos Rousseau que, na Nova Heloísa, dá testemunho "da escalada das montanhas alpinas como se se tratasse de uma vivência de arrebatamento físico, psicológico e moral" (Leonel Ribeiro dos Santos, 2006: 11). Será este mesmo sentimento de arrebatamento que Peter Singer evoca quando admite:

"Contemplei quadros do Louvre e em muitas outras grandes galerias da Europa e dos Estados Unidos. Creio que tenho um razoável sentido de apreciação das belas-artes. Contudo, não tive em museu algum experiências que tivessem preenchido o meu sentido estético a tal ponto realizantes como quando caminho por um cenário natural e faço uma pausa para admirar do alto de um pico rochoso a paisagem de um vale

\footnotetext{
${ }^{1}$ Sagoff argumenta que fruir esteticamente as comunidades ecológicas ou valorizá-las moralmente significa encontrar nelas ou nas suas qualidades, as razões que justificam a sua protecção (1991).
} 
coberto de floresta (...). Creio não ser o único a sentir tal exaltação; para muita gente, a Natureza constitui a fonte dos mais altos sentimentos de emoção estética, elevando-se a uma intensidade quase espiritual." (Peter Singer, 2000: 295)

Enumerar testemunhos sobre a relação entre a experiência do belo natural e a dimensão axiológica da representação do mundo seria tarefa interminável e não relevante. Destacaremos, por isso, na grande maioria desses relatos a comum referência ao elemento fusional presente na apreciação estética da natureza que faz sentir o sujeito na natureza e parte da natureza e não propriamente diante dela, como quando está diante de uma pintura pendurada na parede (R. Hepburn in A. Veríssimo Serrão (coord.), 2011: 234).

Envolvimento, comprometimento, arrebatamento, completude, incorporação constituem termos que, com frequência, caracterizam a vivência estética do mundo natural, distinguindo-a da contextualidade da arte que se configura no enquadramento e distanciamento do objecto artístico. Será, porventura, nessa re-vivência, ou seja, nessa potência de reavivamento emocional de uma unidade fusional perdida ou na ilusão dessa unidade (Sell in A.V.Serrão (coord.), 2011: 411) que a defesa do meio natural colhe mais pela via da estética do que pela da ética, como testemunha Baird Callicott.

Não sendo intenção nossa perdermo-nos no debate acerca das especificidades da estética natural, debate esse importantíssimo, aliás, no momento em que a obsessão industrializadora obnubilou, até certo ponto, o valor estético do ambiente, avançaremos para o questionamento que indaga sobre a relação estrutural entre a estética e a ética ambientais, tendo em mente as palavras de Kant que, na Crítica do Juizo (§ 42), afirma:

"Tomar interesse imediato pela beleza da Natureza é sempre sinal de boa alma; e, se este interesse é habitual, pelo menos indica uma disposição de ânimo favorável ao sentimento moral. (...) Podemos considerar como uma amabilidade que a natureza teve em relação a nós, o facto de ela ter distribuído com tanta abundância, para além do que é útil, ainda a beleza e o encanto e por isso a amamos, da mesma forma que a contemplamos com respeito por causa da sua imensidão e nos sentimos enobrecidos nesta contemplação."

\section{II}

Um olhar de relance pelas teses de eticistas na esteira de Leopold (Callicott, Rolston, Hargrove, Sagoff, entre outros), confirma a tese de mútua implicação entre a estética e a ética ambientais. Com efeito, quan- 
do Leopold afirma que "algo é bom quando tende a preservar o equilíbrio, a integridade e a beleza da comunidade biótica" (Leopold, 2008:206) condensa diferentes planos semânticos num mesmo horizonte significativo - se a beleza se impõe como presença ontológica no mundo, ela constituir-se-á, por isso, como fundamento de moralidade, um imperativo do agir.

Nesse deslizar da ética para uma estética da terra, Leopold sustenta que o gosto refinado pelos objectos naturais constitui a dimensão estrutural da ética da terra que emerge, como na arte, da atracção induzida pelo gracioso, expandindo-se através de sucessivos patamares de beleza até valores intraduzíveis pela linguagem (Callicott, 1987:158). No entanto, para o autor, o apuramento de uma sensibilidade espontânea exige o conhecimento e a informação esclarecedoras, daí que afirme que só a compreensão dos processos ecológicos habilita a apreender a beleza na acepção contextual que lhe é própria, intensificando a sua experienciação que, nesse subtil intercâmbio da cognição e da sensibilidade, se manifesta em completude multi-sensorial de sons, texturas, sabores, odores e cores.

Ainda que poderosamente sugestivo, o apelo ao valor estético para a preservação da natureza confronta-se com dificuldades de vária ordem quando se passa para o plano da fundamentação teórica, pois, apesar da omnipresença espácio-temporal do belo natural, é todavia inegável a sua dependência estreita de preferências, idiossincrasias, contextos culturais e, por isso, não se afigura simples determinar os critérios definidores de uma estética natural, ou a relação do valor estético com os outros tipos de valor (moral e instrumental) ou, mais importante ainda, atingir alguma consensualidade na defesa do belo natural em si relativamente aos espaços arquitecturais, como um jardim ou um plano urbanístico, por exemplo.

Com efeito, a remissão do conceito de belo natural para uma natureza pristina - enquanto lugar do belo em estado puro - parece constituir uma tentação a que não escapam reconhecidos autores da estética ambiental, nomeadamente, Allen Carlson que delineia uma estética positiva a partir da assunção de quatro teses fundacionais (Ned Hettinger, 2005):

1 - A tese da beleza intrínseca: a natureza virgem tem sobretudo qualidades estéticas positivas.

2 - A tese dos juízos não negativos: os juízos negativos acerca da natureza são inapropiados.

3 - A tese do igualitarismo estético: tudo na natureza é valorizável esteticamente de igual modo.

4 - A tese da perfeição estética: a natureza tem um valor estético superlativo. 
Para Carlson, a apreciação estética da natureza radica numa interacção física que apela não só para todos os sentidos, mas também para o conhecimento apropriado dos objectos de apreciação, não privilegiando configurações naturais específicas. Defendendo que toda a apreciação estética envolve uma apreciação cognitiva, o autor argumenta que este tipo de experienciação sensível requer a mediação do conhecimento dos processos de formação e de evolução das realidades naturais, como factor de elucidação e refinamento da sensibilidade, que deste modo descobre a natureza tal como a ciência a interpreta, ou seja, no seu significado simbiótico, equivalente a ordem, regularidade e harmonia. Segundo Carlson, esse significado traduz a verdade do objecto de apreciação, porquanto a ciência é a fonte da verdade objectiva, revelando e desvendando as propriedades intrínsecas dos objectos sob a aparência da imagem. Tal como para Leopold, que reclama por uma literacia ecológica na apreciação da estética natural, contemplar uma montanha é, para Carlson, algo mais do que ver árvores, cores, flores; é, também, compreender a sua história natural, as suas populações específicas e as relações que a animam.

Porém, a alegação de uma natureza intocada onde a beleza floresce em múltiplas formas próprias e em todas as suas partes, parece ignorar o facto da omnipresença humana no mundo e a correspondente influência global da sua acção como factor de inegável afecção de toda a superfície planetária. Em consequência, o que Carlson apresenta como tese - a de que a natureza virgem possui uma mais-valia estética relativamente à intervencionada pelo homem - colocar-se-á sobretudo como conjectura. $\mathrm{Na}$ realidade, onde está a natureza virgem? Escorar uma teoria em conjecturas constitui um claro enfraquecimento da sua solidez argumentativa, daí que a defesa de Carlson em prol de uma estética positiva não escape a uma "chuva" de objecções.

No entanto, dois aspectos há nesta teoria que nos merecem particular atenção: por um lado, a introdução da razão cognitiva na leitura do belo natural, por outro a relação que aí se afirma entre o ético e o estético.

Com efeito, se a apreciação estética da natureza não carece de uma literacia ecológica para que uma realidade natural $\mathrm{x}$, seja ela qual for, se apreenda como bela, a inclusão do valor estético no discurso preservacionista reclama o entendimento desse valor no seu significado temporal, o que pressupõe o conhecimento da sua performance adaptativa ao longo de toda a sua história evolutiva. Tratar-se-á, de um contexto semântico que pode, com efeito, libertar a apreciação da natureza de uma perspectiva culturalmente estereotipada, de raiz pictórica ou panorâmica, que, como deplora Leopold, rotula alguns lugares de "chatos" ou de "entediantes" e outros de "espectaculares" ou de "extraordinários". Assim, muito embora os critérios biológicos ou ecológicos, de ordem factiva, sejam irredutíveis à dimensão valorativa da experiência estética, o valor ecoló- 
gico constituiria um modo, simultaneamente intensivo e extensivo, de contextualização do valor estético da natureza, oferecendo à espontaneidade sensível da contemplação do mundo natural, um roteiro objectivante de orientação e de ordem.

Por outro lado, não podemos deixar de aqui sublinhar a presunção deste autor de que a apreciação estética da natureza é um precioso auxiliar na modelação da dimensão ética do mundo natural, contribuindo para o desenvolvimento de atitudes de respeito e de protecção ecológicas. No mesmo sentido, chamamos Martin Sell que, sobre o tema, se pronuncia nestes termos "a estética da natureza explicitada revela-se como parte de uma ética geral da vida boa" (in A. V. Serrão (coord.), 2011: 397). E, essa parte, presumimos nós, é de ordem fundacional porquanto acreditamos que é pela via da estética natural que, emocionalmente, se estabelece um laço entre o ser humano e a natureza de recíproca dependência e solidariedade que propicia sentimentos de amor e respeito para com ela.

Daí que assumamos a confinidade entre os valores estéticos e os valores morais e afirmemos a fecundidade da sua efectiva articulação no debate ambiental e na preservação de realidades naturais. Corroborando Emily Brady (2003) também cremos que a experiência estética é a forma mais directa e comum de valorização da natureza, potenciando uma atitude de cuidado para com ela. Uma perspectiva crítica da estética ambiental conduzirá, porventura, a uma visão mais ampla dos matizes do belo que, como admite Rolston, Brady ou Berleant, pode passar pelo feio ou o chocante propiciando uma apreciação valorativa igualmente marcante, quer se esteja na presença de uma borboleta ou de um escaravelho, por exemplo; ou perante um pôr-do-sol no mar ou em frente a um pântano sob um manto de nuvens cinzentas ${ }^{2}$. A este respeito, Arnold Berleant lembra que na natureza, tal como na arte, o feio tem também a sua beleza, porquanto não é a perfeição que define a qualidade estética do mundo natural, mas sim a sua infinita variedade, a riqueza das suas múltiplas formas e o seu carácter único e singular.

Dado o exposto, retenhamos duas considerações. Em primeiro lugar, não nos oferece dúvida alguma o juízo de que a contemplação do belo natural é uma experiência fortemente significativa para a maior parte dos seres humanos, em segundo lugar, a intensidade dessa significação leva-nos a crer que é na vivência do belo natural que reside o primeiro movimento, porque espontâneo, gratuito, e sensível, para o agir ético. Como

2 "Visito este pântano, pelo menos, uma vez em cada estação. As plantas não são, segundo os padrões de jardinagem bonitas (...). A beleza deste pântano (...) é uma função (...) das interconexões dos seus componentes. (...) Há um ajustamento perceptível, uma unidade aí não muito diferente de uma sinfonia ou de uma tragédia" (Callicott, 1987:166). 
tantos testemunham, a emoção que se experimenta na contemplação de uma paisagem natural, conduz ao sentimento de ligação com a vida, um sentir-com-todas-as-coisas, que, cremos, constitui a dimensão fundante de uma ética de respeito e de não-dominação. Neste ponto, regressemos a Kant (A Metafisica dos Costumes), e ouçamo-lo:

"No que respeita ao belo da natureza, ainda que inanimado, a tendência para o mero destruir é contrária ao dever do homem para consigo próprio; porque enfraquece ou extermina no homem aquele sentimento, que, embora não sendo por si apenas já [um sentimento] moral, prepara todavia este, na medida em que promove muito aquela disposição da sensibilidade que nos leva a amar algo sem ter em vista a utilidade." (in Leonel Ribeiro dos Santos, 2006:25)

Se a racionalidade firme e austera impende sobre a conduta moral humana, a Natureza, para Kant, pela beleza e sublimidade com que se oferece ao homem, convoca neste o amor desinteressado e a superlativa estima que aqui se compreeendem como dimensões anunciativas do sentimento moral. Assim, é neste suscitar de apreço adveniente da graciosa relação entre o homem e a natureza que Kant reconhece a íntima solidariedade entre a experiência do belo natural e o sentimento moral, enquanto experiência constitutiva de uma "boa alma" que, por isso, se apresenta como instância preparatória e matricial de uma vontade boa.

Para o filósofo de Königsberg, e aqui citamos Leonel Ribeiro dos Santos (2006:25), "a responsabilidade do homem pela natureza entende-se menos num sentido moralista ou jurídico e mais no sentido de uma mudança radical da atitude humana frente à natureza, a qual passa do confronto agressivo ao diálogo, da dominação voluntarista à atenção vigilante e respeitadora, da exploração e usufruto destruidor à disponibilidade para aceitar e agradecer o dom, a graça e os favores que a natureza espontânea e prodigamente nos dispensa".

Ora é neste encontro entre o homem e a natureza, mediado pela experiência estética e pela experiência do sublime, que se oferece à humanidade a oportunidade de descobrir a satisfação desinteressada e vislumbrar o incondicionado da liberdade presente no acto moral. Enquanto instrumento de revelação e de abertura ao Bem e ao Divino, a natureza constitui-se aqui como plano de transição entre a atracção sensível e a moralidade, e, por isso, caminho de possibilidade realizante do ser humano, que apenas se assume plenamente, e em consciência, na comunidade moral. Neste sentido, o respeito deve incluir a natureza não tanto pelo que ela é em si mesma, mas sobretudo pelo que ela é para o homem - o espelho da sua autêntica humanidade, isto é, liberdade e amor desinteressado. 


\section{Conclusão}

Apesar do influente texto seminal de Leopold apontar para a fulcralidade da estética na abordagem ética ao mundo natural e de autores ambientais sublinharem a relação entre o belo natural e o agir, a ética ambiental relegou para um plano secundário o tema dos valores estéticos que, a maior parte das vezes, surge mais como a "cereja em cima do bolo" (Brady:2005), ou seja, como apontamento marginal de uma fundada reflexão sobre o estatuto axiológico dos entes naturais no contexto da acção, do que como um tipo de valor inerente à relação do homem com a natureza que possui a virtualidade de induzir no ser humano comportamentos de consideração e respeito.

Parece, no entanto, evidente como aponta Rolston (in Allen Carlson \& Sheila Lintott (ed.), 2008: 333), que onde existe uma experiência estética desejável também existe, em consequência, o desejo de a preservar.

Assumindo a estética natural como a via relacional mais imediata e intuitiva entre o homem e a natureza, como canal comunicacional que interpela o ser humano a responder afectivamente ao mundo, como, ainda, um campo de experienciação multiestésica em que a cognição e a sensibilidade abrem o caminho para o bem agir, então pode presumir-se que a estética natural constitui a dimensão estrutural da ética do ambiente, o seu suporte e fundamento primeiro. Neste sentido, o desenvolvimento reflexivo da estética ambiental, a sua reavaliação como componente inerente à acção, pode, de facto, constituir uma base consistente na defesa e preservação do mundo natural, ao mesmo tempo em que afirma o ser humano na sua inteireza, emocional e afectiva, cuja resposta ao belo natural se apreende como vocação originária que desvenda, ampliando, o significado e sentido da sua humanidade. E é deste modo, quanto a nós, que o belo natural se apresenta como possibilidade exemplar da vida do homem (Sell in A.Veríssimo Serrão (coord.), 2011).

\section{ABSTRACT}

This paper defends that environmental aesthetics provides a consistent basis for environmental philosophy, whereas aesthetic value plays an important role in the defense and preservation of natural areas. For several environmental philosophers the natural beauty is an inherent part of the ethical concern. Leopold states that "a thing is right when it tends to preserve the integrity, the balance and the beauty of the biotic community". Notwithstanding, aesthetic value is still not a central issue in the environmental debate. On the other hand, the "positive aesthetics" (Allen Carlson), which is a recent approach that reevaluates "positively" natural beauty in the ethical context, obtains a core of objections. This paper sketches a few arguments defending the contiguity 
between environmental aesthetics and environmental ethics: (i) the emotional perception of inclusiveness and engagement on the aesthetics appreciation of nature; (ii) the feelings of grace and love toward nature inherent to the nature's aesthetic appreciation which according Kant announces the moral feeling; (iii) the ecological knowledge of natural beauty in order to understand the full meaning of it, and that includes some natural entities seen as not beautiful.

Palavras-chave: estética natural, belo natural, sentimento moral, Kant, ética ambiental, apreciação estética da natureza, estética positiva, preservação ecológica

\section{Referências bibliográficas}

Brady, Emily, April 2005, "Aesthetics in Practice: Valuing the Natural World" (pág. elect.).

Brady, Emily, 2003, Aesthetics of the natural environment, Edinburgh: Edinburgh University Press, Ltd.

Berleant, Arnold, 1992, The Aesthetics of Environment, Philadelphia: Temple University Press.

Callicott, 1987, Companion to a Sand County Almanac, Madison: The University of Wisconsin Press.

Carlson, A., \& Lintott, S., 2008, Nature, Aesthetics and Environmentalism, 2008, New York: Columbia University Press.

Hettinger, Ned, 2005, “Allen Carlson's Environmental Aesthetics and the Protection of the Environment”, Environmental Ethics, 27 (Spring 2005): 57-76.

Kant, 1992, Crítica da Faculdade do Juízo, trad. A. Marques, Lisboa: Imprensa Nacional.

Leopold, Aldo, (1949, A Sand County Almanac, London/ Oxford/ N. York: Oxford University Press) ed. portuguesa: 2008, Pensar Como uma Montan$h a$, trad. Ed. Sempre-em-Pé, Águas Santas: Ed. Sempre-em-Pé.

Sagoff, Mark, 1991, “Zuckerman's Dilemma: A Plea for Environmental Ethics" in Hastings Center Report, vol. 21, n 5, pp. 32-40.

Santos, Leonel Ribeiro dos, "Da Experiência Estético-Teológica da Natureza à Consciência Ecológica: Uma Leitura da Crítica do Juízo de Kant”, in Trans/Form/Ação, S. Paulo, 29 (1): 7-29, 2006.

Serrão, Adriana Veríssimo (coord.), 2011, Filosofia da Paisagem. Uma Antologia, Lisboa: Centro de Filosofia da U. L.

Singer, Peter, (1993) 2000, Ética Prática, trad. Álvaro Augusto Fernandes, Lisboa: Gradiva.

Varandas, Ma . José, 2009, Ambiente, uma questão de ética, Lisboa: Esfera do Caos.

Varandas, Ma José, in Serrão, Adriana Veríssimo, (coord.), Manual de Filosofia e Arquitectura da Paisagem (no prelo). 